\title{
Effects of High Glucose Concentrations on the Endothelial Function of the Renal Microcirculation of Rabbits
}

\author{
Filipe de Souza Affonso, Solange Cailleaux, Leonardo Felipe Corrêa Pinto, \\ Marília de Brito Gomes, Eduardo Tibiriçá
}

Rio de Janeiro, RJ - Brazil

\begin{abstract}
Objective - To assess the acute effects of high glucose concentrations on vascular reactivity in the isolated non diabetic rabbit kidney.
\end{abstract}

Methods - Rabbits were anaesthetized for isolation of the kidneys. Renal arteries and veins were cannulated for perfusion with Krebs-Henselleit solution and measurement of perfusion pressure. After 3 hours of perfusion with glucose 5,5 $\mathrm{mM}$ (control) and $15 \mathrm{mM}$, the circulation was submitted to sub maximal precontraction (80\% of maximal response) trough continuous infusion of noradrenaline $10 \mathrm{mM}$. Vascular reactivity was then assessed trough dose-responses curves with endothelium-dependent (acetylcholine) and independent (sodium nitroprusside) vasodilators. The influence of hyperosmolarity was analyzed with perfusion with mannitol $15 \mathrm{mM}$.

Results - A significant reduction in the endotheliumdependent vasodilation in glucose $15 \mathrm{mM}$ group was observed compared to that in control, but there was no difference in endothelium-independent vasodilation. After perfusion with mannitol $15 \mathrm{mM}$, a less expressive reduction in endothelium-dependent vasodilation was observed, only reaching significance in regard to the greatest dose of acetylcholine.

Conclusions - High levels of glucose similar to those found in diabetic patients in the postprandial period can cause significant acute changes in renal vascular reactivity rabbits. In diabetic patients these effects may also occur and contribute to diabetes vascular disease.

Keywords: endothelial dysfunction, hyperglycemia, renal circulation

Hospital Universitário Pedro Ernesto - UERJ; Laboratório de Farmacologia NeuroCardiovascular - Departamento de Fisiologia e Farmacodinâmica - Instituto Oswaldo Cruz, FIOCRUZ.

Mailing address: Eduardo Tibiriçá - Laboratório de Farmacologia Neuro Cardiovascular - Fiocruz - Av Brasil, 4365 - CP 926 - 21045-900 - Rio de Janeiro, RJ, Brazil. English version by Stela Maris C. e Gandour
Diabetes mellitus is currently considered an important public health problem due to an increase in its prevalence. The disease and its chronic micro- and macrovascular complications cause high direct and indirect costs, impairing productivity and quality of life and resulting in higher morbidity and mortality rates. The prevalence of diabetes mellitus has been increasing in developed and developing countries. In Brazil, data from the multicenter study about diabetes mellitus have shown a $7.6 \%$ prevalence of the disease in the population aged 30 to 69 years, and in the year 2010 an approximate diabetic population of 11 million people is estimated to exist in the country, representing a 100\% increase compared with the current diabetic population of 5 million people ${ }^{1}$.

The high morbidity and mortality of patients with diabetes mellitus depends on the chronic complications, which involve several tissues, impairing the micro- and macrovasculature. In fact, diabetes mellitus contributes to most cases of terminal renal disease in the Western world, and is also the major cause of acquired blindness and of diseaserelated amputations of the lower limbs. After the discovery of insulin in 1921, cardiovascular diseases became the major cause of morbidity and mortality in diabetic individuals ${ }^{2}$. According to the Framingham study ${ }^{3}$, over $50 \%$ of the mortality in diabetic patients relates to cardiovascular diseases, and the incidence of cerebrovascular and coronary artery diseases is 2- to 4-times greater in diabetic patients than in the general population. In addition, the diabetic patients developing cardiovascular diseases have a poorer prognosis and greater mortality ${ }^{47}$.

Currently, a series of evidence indicates that the physiopathogeny of the vascular disease in diabetes mellitus is associated with endothelial dysfunction. Studies about the presence of endothelial dysfunction in diabetic patients have been controversial, which may be attributed to differences in the methods used for its detection ${ }^{8}$. On the other hand, most experimental studies have shown changes in the endothelial physiology induced by elevated concentrations of glucose, although these concentrations were extremely 
high compared with the glucose levels frequently found in the management of diabetic patients ${ }^{9-30}$.

The present study aimed at assessing the acute effects of the high concentrations of glucose routinely found in diabetic patients in daily clinical practice on the reactivity of the renal microcirculation of nondiabetic rabbits.

\section{Methods}

New Zealand albinistic rabbits were anesthetized with sodium pentobarbital $(40 \mathrm{mg} / \mathrm{kg}$, I.V.), immobilized with pancuronium bromide $(1 \mathrm{mg} / \mathrm{kg}, \mathrm{I}$.V.) to allow mechanically controlled ventilation, and received heparin (500 IU/kg, I.V.). After a median laparotomy, both kidneys were isolated and the renal arteries and veins were catheterized. Then, the kidney was placed in a Petri dish and the renal artery was perfused with the nutrient Krebs-Henseleit solution gassed with carbogenium $\left(95 \% \mathrm{O}_{2}-5 \% \mathrm{CO}_{2}\right)$ at a constant flow $(4 \mathrm{~mL} /$ $\mathrm{min}$ ) for later measurement of the perfusion pressure. After inducing precontraction of the renal circulation with continuous perfusion of noradrenalin $(10 \mu \mathrm{M})$, dose-response curves were recorded for assessing the vasodilating effect of the 2 following substances: acetylcholine (endotheliumdependent vasodilation) and sodium nitroprusside (endothelium-independent vasodilation). The perfusion line was connected to a pressure transducer (7016 model, Ugo Basile, Comerio, Italy) and the modifications in the perfusion pressure were continuously measured and then recorded on a 2-channel polygraph recorder (Gemini 7070, Ugo Basile, Comerio, Italy). The composition of the Krebs-Henseleit solution used was (in mM): $118 \mathrm{NaCl}, 4.7 \mathrm{KCl}, 1.17 \mathrm{MgSO}_{4}$, $2.5 \mathrm{CaCl}_{2} 6 \mathrm{H}_{2} \mathrm{O}, 1.2 \mathrm{NaH}_{2} \mathrm{PO}_{4}, 25 \mathrm{NaHCO}_{3}, 5.5$ glucose, and $0.25 \%$ bovine serum albumin ( $\mathrm{pH} 7.4)$.

The rabbit renal circulation was perfused with different concentrations of glucose solutions for 3 hours. Two groups were formed as follows: one receiving a physiological concentration of glucose (5.5 mM, control group) and another receiving a high concentration of glucose $(15 \mathrm{mM})$, which corresponded to the mean postprandial glycemia of a certain population of diabetic patients followed up at the outpatient care unit for diabetes of the Hospital Universitário Pedro Ernesto of the Universidade do Estado do Rio de Janeiro. After perfusion, submaximal precontraction ( $80 \%$ of the maximal response) of the renal circulation was induced through continuous infusion of noradrenaline $(10 \mu \mathrm{M})$, and, then, increasing doses of acetylcholine $\left(10^{-7}-10^{-5} \mathrm{~mol}\right)$ were administered in the line for renal perfusion to determine the endothelium-dependent vasodilating responses.

The same protocol described was used to assess the endothelium-independent vasodilating response. Sodium nitroprusside (0.1-2.5 mg), a substance that donates nitric oxide and whose vasodilating effect does not depend on the integrity of the vascular endothelium was administered in the line for renal perfusion to record the dose-response curves.

The renal circulation was perfused for 3 hours with solutions with the same osmolarity of the high concentra- tion glucose solution $(15 \mathrm{mM})$. For this, mannitol was added to the $5.5 \mathrm{mM}$ glucose solution. After perfusion, submaximal precontraction ( $80 \%$ of the maximal response) of the renal circulation was induced through continuous infusion of noradrenaline $(10 \mu \mathrm{M})$, and increasing doses of acetylcholine $\left(10^{-7}-10^{-5} \mathrm{~mol}\right)$ were administered in the line for renal perfusion to record the dose-response curve.

The drugs used were as follows: acetylcholine chloride, $( \pm)$-arterenol hydrochloride (noradrenaline), sodium nitroprusside, mannitol, D-glucose, sodium pentobarbital (Sigma Chemical Co., St. Louis, MO, USA), and pancuronium bromide (Pancuron, Cristália, Brazil).

The results were shown as mean \pm MSE for each group. Determination of the significant differences between the groups was performed with analysis of variance (ANOVA). When a significant difference was detected with ANOVA, the Student-Newman-Keuls test was used to locate the significant differences. Differences with a P value lower than 0.05 were considered significant. The statistical calculations were performed with Graphpad Instat (Graphpad Software, London University, England) software.

\section{Results}

Figure 1 illustrates the effects of the perfusion with a high concentration glucose $(15 \mathrm{mM})$ solution on endothelium-dependent vasodilation. The relaxation induced by acetylcholine was significantly lower in the group perfused with a $15 \mathrm{mM}$ glucose solution compared with that in the control group $(\mathrm{P}<0.05)$, and a maximal reduction of $24.5 \pm$ $3 \%$ in the perfusion pressure was reached compared with the maximal reduction of $41 \pm 4 \%$ in the control group.

Figure 2 shows the effects of different concentrations of glucose on endothelium-independent vasodilation. No significant differences between the control $(5.5 \mathrm{mM})$ and the high glucose $(15 \mathrm{mM})$ groups were observed.

Figure 3 shows the effects of hyperosmolarity $(15 \mathrm{mM}$ mannitol) on endothelium-mediated vasodilation. A nonsignificant reduction in acetylcholine-induced relaxation occurred compared with that in the control group, except for

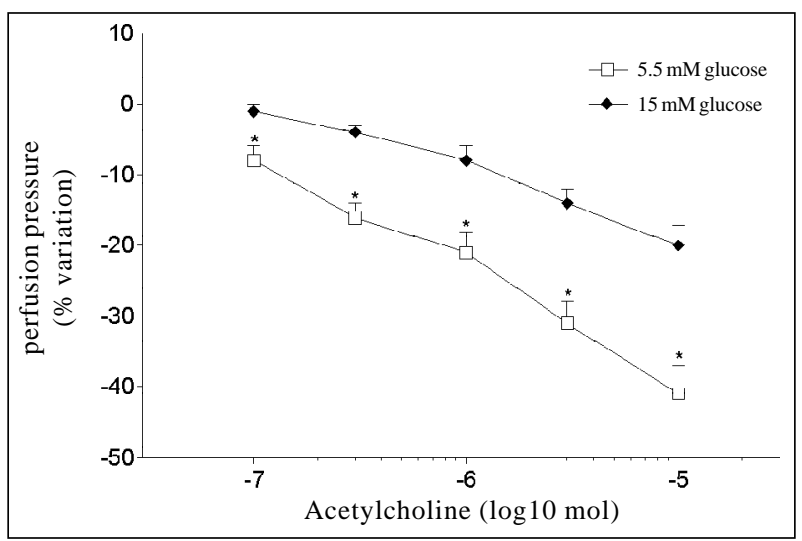

Fig. 1 - Acetylcholine-induced relaxation in the control ( $5.5 \mathrm{mM}$ glucose, $\mathrm{n}=6)$ and high glucose $(15 \mathrm{mM}, \mathrm{n}=6)$ groups in the isolated and perfused rabbit kidney. The point represents the mean $\pm \mathrm{MSE} ; * \mathrm{P}<0.05$ compared with the control group. 
the dose of $10^{-5} \mathrm{~mol}$, in which a significantly lower reduction in the perfusion pressure occurred in the $15 \mathrm{mM}$ mannitol group. The maximal reduction in the perfusion pressure in the $15 \mathrm{mM}$ mannitol group was $30 \pm 3 \%$ compared with $41 \pm 4 \%$ in the control group.

\section{Discussion}

It has been established that the endothelium plays critical roles in homeostasis in the body, because it can secrete several chemical mediators and interact with vascular smooth muscle cells and with elements present in the circulation, such as the hematopoietic cells. The major endothelial functions are as follows: 1) control of the vascular tonus through the secretion of vasoactive substances; 2) regulation of the growth of vascular smooth muscle cells; 3 ) participation in inflammatory reactions; and 4 ) hemostasia ${ }^{31,32}$.It is not surprising that several factors, such as smoking, systemic arterial hypertension, dyslipidemia, hyperhomocysteinemia, and hyperglycemia itself, implicated in the pathogeny of vasculopathies have in common the presence of

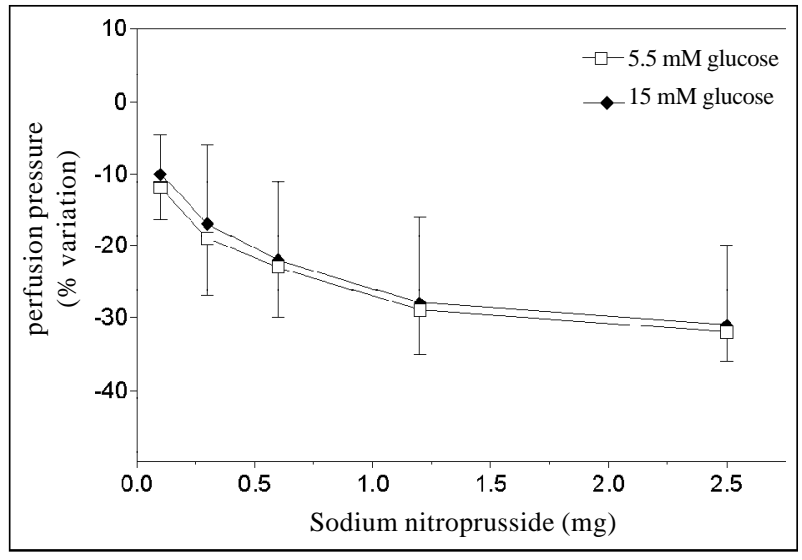

Fig. 2 - Sodium nitroprusside-induced relaxation in the control $(5.5 \mathrm{mM}$ glucose, $\mathrm{n}=$ 4) and high glucose $(15 \mathrm{mM}, \mathrm{n}=4)$ groups in the isolated and perfused rabbit kidney. The point represents the mean \pm MSE; no significant differences were observed between the groups $(\mathrm{P}>0.05)$.

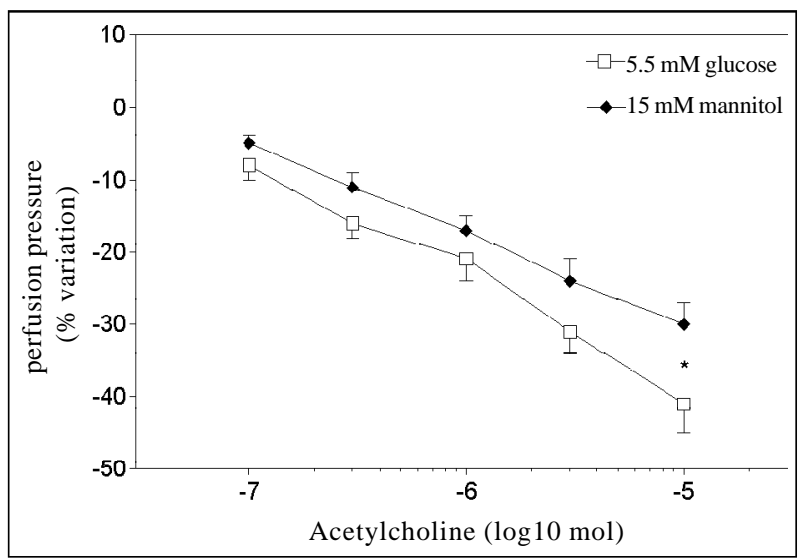

Fig. 3 - Acetylcholine-induced relaxation in the control group (5.5 mM glucose) and in the group receiving $15 \mathrm{mM}$ mannitol. The point represents the mean $\pm \mathrm{MSE}$; * $\mathrm{P}<0.05$ compared with the control group. perturbations in endothelial physiology. In diabetic patients, a complex interaction of factors, such as hyperglycemia, systemic arterial hypertension, dyslipidemia, and hyperinsulinemia/insulin resistance, causing endothelial dysfunction usually exists mainly in type 2 diabetes ${ }^{8,33}$. In type 1 diabetes, the major agent seems to be hyperglycemia ${ }^{8,33}$, which proved to be an important factor for microvascular complications in patients with type 1 diabetes mellitus in the DCCT $^{34}$ (Diabetes Control and Complications Trial) and Steno ${ }^{35}$ studies and in type 2 diabetic patients as reported in the UKPDS ${ }^{36}$ (United Kingdom Prospective Diabetes Study). Hyperglycemia may also play a role in the pathogenesis of macrovascular complications ${ }^{37,38}$.

One of the major vasoactive mediators released by the endothelial cell is nitric oxide, which has several antiatherogenic effects, such as a reduction in platelet aggregation, inhibition of the secretion of growth factors and molecules of endothelial adhesion, and stimulation of the inhibitor of the $\kappa \mathrm{B}$ nuclear transcription factor, $\mathrm{I} \kappa \mathrm{B} \alpha^{8,33}$. Several experimental studies and studies in human beings with diabetes mellitus have shown a reduction in endothelial nitric oxide, which may be attributed to several causes. Hyperglycemia has a set of mechanisms that potentially reduces endothelial nitric oxide, including the reduction in the activity of nitric oxide synthase due to depletion of NADPH. The latter is caused by the activation in the polyol route, the activation of PKC, and the increase in oxidative stress, leading to inactivation of nitric oxide with formation of nitrite peroxide ${ }^{8}$. It is the current consensus to consider that endothelial dysfunction may contribute both to microangiopathy and macroangiopathy of diabetes mellitus ${ }^{8,33}$.

The endothelial cell has multiple functions, and no singular definition of endothelial dysfunction exists ${ }^{8}$. The various definitions found in the studies range from functional alterations, mainly the capacity of vasodilation induced by substances or by maneuvers that stimulate the secretion of nitric oxide by the endothelium, to changes in the amount of chemical mediators produced by the endothelial cell. In that context, endothelial dysfunction has been typically defined as a reduction in the vasodilating response to acetylcholine (or to metacholin) or to reactive hyperemia, which causes the release of nitric oxide by the endothelium. The determination of the levels of substances derived from the endothelium, such as endothelin, thrombomodulin, and the von Willebrand factor, should also be carefully interpreted, because their alterations may reflect changes in the synthesis or breakdown of these mediators ${ }^{8,33}$.

Functional studies in diabetic patients have reported conflicting results ${ }^{8}$. Several obstacles, from ethical to methodological, have made these studies difficult. The most reliable method of assessing blood flow in human beings, which is measurement with an intravascular catheter, is invasive, expensive, risky for the patient, and performed only in a few research centers ${ }^{8}$. In general, the cost, subjectivity, and absence of validation have challenged the reliability of other functional methods. Some studies, such as that by Johnstone et al $^{39}$, assessing the reactivity of vessels 
of resistance in the forearm of type 1 diabetic patients, reported a reduction in the vasodilating response to acetylcholine compared with that in the control group, while the vasodilating responses to sodium nitroprusside and to verapamil were similar in both groups. On the other hand, Smiths et $\mathrm{al}^{40}$ and Halkin et $\mathrm{al}^{41}$ found no reduction in endothelium-dependent vasodilation in type 1 diabetic patients.

The most different methodologies concerning the evaluation of the presence of alterations in endothelial function caused by glucose have been applied in experimental studies. In this regard, in vivo studies with diabetic animals ${ }^{9}$, studies with isolated organs (for example: aortic rings) of diabetic animals ${ }^{10-15}$, with isolated organs of nondiabetic animals exposed to high concentrations of glucose for a certain period of time ${ }^{16-20}$, and with cultures of endothelial cells exposed to a medium with high concentrations of glucose exist ${ }^{21-30,42-44}$.

Several studies did not include control with osmotic substances, but with nonabsorbable substances metabolized by the cell (ex: mannitol) ${ }^{21,27,28}$. This generated doubts about whether the alterations found were specifically due to glucose or hyperosmolarity of the medium. Our study showed that hyperosmolarity can cause a reduction in endothelium-dependent vasodilation, although the latter was significant only in the highest dose of acetylcholine and had lower intensity compared with the reduction caused by the $15 \mathrm{mM}$ glucose concentration. In addition, the glucose concentrations used in the various studies were very high compared with those routinely found in clinical practice ${ }^{9-30}$. On the contrary, in our study, we found the presence of acute endothelial dysfunction in concentrations similar to those routinely found in diabetic patients, mainly in the postprandial period, confirming the importance of postprandial glycemic levels in the pathogenesis of the chronic complications of the disease. Recently, the DECODE Study ${ }^{45}$ (Diabetes Epidemiology: Collaborative Analysis of Diagnostic Criteria in Europe) reported that postprandial hyperglycemia was the best predictor of mortality in type 2 diabetic patients. We also emphasize that, so far, most studies have been performed in conductance vessels (macrovasculature), and the literature about the alterations in reactivity of the microcirculation mediated by glucose is scarce. We studied a structure whose damage from diabetes mellitus is well known: the renal microcirculation. And we observed that high levels of glucose can interfere with the normal endothelial physiology in microcirculation.

In conclusion, high levels of glucose similar to those found in diabetic patients in the postprandial period can cause acute significant alterations in the endothelium of the renal microcirculation in nondiabetic rabbits. These effects may also occur in diabetic patients and, in the long run, may contribute to the physiopathogeny of the vascular disease of diabetes mellitus.

\section{Acknowledgement}

We thank our work colleague Rodrigo Cavalheiro da Silva for his support, and the financial support of the FIOCRUZ/FAPERJ partnership.

\section{References}

1. Brasil. Ministério da Saúde. Hipertensão Arterial Sistêmica (HAS) e Diabetes Mellitus (DM): Protocolo/ Departamento de Atenção Básica. Área Técnica de Diabetes e Hipertensão Arterial, 2001.

2. Krolewski AS, Warram JH, Rand LI, Khan CR. Epidemiologic approach to etiology of type 1 diabetes and its complications. N Engl J Med 1987; 317: 1390-8.

3. Kannel WB, McGee DL. Diabetes and cardiovascular disease: the Framingham study. JAMA 1979; 241: 2035-8.

4. Stone PH, Muller JE, Hartwell T, et al, and the Milis Study Group. The effect of diabetes mellitus on prognosis and serial left ventricular function after acute myocardial infarction: contribution of both coronary disease and diastolic left ventricular dysfunction to the adverse prognosis. J Am Coll Cardiol 1989; 14: 49-57.

5. Singer DE, Moulton AW, Nathan DM. Diabetic myocardial infarction: interaction of diabetes with other preinfarction risk factors. Diabetes 1989; 38: 350-7.

6. Smith JW, Marcus FI, Serokman R. Prognosis of patients with diabetes mellitus after acute myocardial infarction. Am J Cardiol 1984; 54: 718-21.

7. Stamler J, Vaccaro O, Neaton JD, Wentworth D. Diabetes, other risk factors, and 12-year cardiovascular mortality for men screened in the Multiple Risk Factor Intervention Trial (MRFIT). Diabetes Care 1993; 16: 434-44.

8. Escandon, JC, Cipolla M. Diabetes and endothelial dysfunction: a clinical perspective. Endocrine Reviews 2001; 22: 36-52.

9. Lash JM, Bohlen HG. Structural and functional origins of suppressed acetylcholine vasodilation in diabetic rat intestinal arterioles. Circ Res 1991; 69: 1259-68.

10. Taylor PD, Oon BB, Thomas CR, Poston L. Prevention by insulin treatment of endothelial dysfunction but not enhanced noradrenaline-induced contractility in mesenteric resistance arteries from streptozotocin - induced diabetic rats. $\mathrm{Br} \mathrm{J}$ Pharmacol 1994; 111: 35-41.

11. Hattori Y, Kawasaki H, Abe K, Kanno M. Superoxide dismutase recovers endothelium dependent relaxation in diabetic rat aorta. Am J Physiol 1991; 261: H1086-94
12. Tesfamariam B, Jakubowkski JA, Cohen RA. Contraction of diabetic rabbit aorta due to endothelium-derived $\mathrm{PGH}_{2} / \mathrm{TXA}_{2}$. Am J Physiol 1989; 257: H1327-33.

13. Oyama Y, Kawaski H, Hamori Y, Kanno M. Attenuation of endothelium-dependent relaxation in aorta from diabetic rats. Eur J Pharmacol 1986; 131: 74-8.

14. Abiru T, Watanabe Y, Kamara K, Miyata N, Kasuya Y. Decrease in endothelium-dependent relaxation and levels of cyclic nucleotides in aorta from rabbits with alloxan-induced diabetes. Res Commun Chem Pathol Pharmacol 1990; 68: 13-25.

15. Pieper GM, Siebeneich W. Oral administration of the antioxidant, $\mathrm{N}$-acetylcysteine, abrogates diabetes-induced endothelial dysfunction. J Cardiovasc Pharmacol 1998; 32: 101-5.

16. Tesfamariam B, Brown ML, Deykin D, Cohen RA. Elevated glucose promotes generation of endothelium - derived vasoconstrictor prostanoids in rabbit aorta. J Clin Invest 1990; 85: 929-32.

17. Tesfamariam B, Brown ML, Cohen RA. Elevated glucose impairs endothelium-dependent relaxation by activating protein kinase C. J Clin Invest 1991; 87: 1643-8.

18. Bohlen HG, Lash JM. Topical hyperglycemia rapidly suppresses EDRF-mediated vasodilation of normal rats arterioles. Am J Physiol 1993; 265: H219-25.

19. Tesfamarian B, Cohen RA. Free radicals mediate endothelial cell dysfunction caused by elevated glucose. Am J Physiol 1992; 263: H 321-6.

20. Dorigo P, Fraccarollo D, Santostasi G, Maragno I. Impairment of endothelium-dependent but not of endothelium-independent dilation in guinea-pig aorta rings incubated in the presence of elevated glucose. Br J Pharmacol 1997; 121: 972-6.

21. Davies MG, Hagen PO. Alterations in venous endothelial cell and smooth muscle cell relaxation induced by high glucose concentrations can be prevented by aminoguanidine. J Surg Res 1996; 63: 474-9.

22. Hattori Y, Hattori S, Sato N, Kasai K. High glucose-induced nuclear factor kappa B activation in vascular smooth muscle cells. Cardiovasc Res 2000; 46: 188-97.

23. Manduteanu I, Voinea M, Serban G, Simionescu M. High glucose induces enhanced monocyte adhesion to valvular endothelial cells via a mechanism involving ICAM-1, VCAM-1 and CD18. Endothelium 1999; 6: 315-24. 
24. Taki H, Kashiwagi A, Tanaka Y, Horiike K. Expression of intercellular adhesion molecules 1 (ICAM-1) via an osmotic effect in human umbilical vein endothelial cells exposed to high glucose medium. Life Sci 1996; 58: 1713-21.

25. Salameh A, Zinn M, Dhein S. High D-glucose induces alterations of endothelial cell structure in a cell-culture model. J Cardiovasc Pharmacol 1997; 30: 182-90.

26. Kashiwagi A, Asahina T, Nishio Y, et al. Glycation, oxidative stress, and scavenger activity: glucose metabolism and radical scavenger dysfunction in endothelial cells. Diabetes 1996; 45(suppl 3): S84-6.

27. Kashiwagi A, Nishio Y, Asahina T, et aI. Pyruvate improves deleterious effects of high glucose on activation of pentose phosphate pathway and glutathione redox cycle in endothelial cells. Diabetes 1997; 46: 2088-95.

28. La Selva M, Beltramo E, Pagnozzi F, Molinatti PA, Molinatti GM, Porta M. Thiamine corrects delayed replication and decreases production of lactate and advanced glycation end-products in bovine retinal and human umbilical vein endothelial cells cultured under high glucose conditions. Diabetologia 1996; 39: 1263-8.

29. Wu QD, Wang JH, Fennessy F, Redmond HP, Bouchier-Hayes D. Taurine prevents high-glucose-induced human vascular endothelial cell apoptosis. Am J Physiol 1999; 277: C1229-38.

30. Khatami M. Kinetics of myo-inositol transport in corneal endothelial cells: diverse effects of sugars and implications in corneal deturgescence. Membr Biochem 1990; 9: 91-106

31. Carvalho MH, Scivoletto R, Nigro D, Fortes ZB. Funções fisiológicas do endotélio vascular. Rev Soc Cardiol Estado de São Paulo 1996; 6: 121-8.

32. Nunes GL, Sousa AG, Sousa JE. Papel do endotélio na regulação da proliferação vascular: implicações na reestenose pós-angioplastia coronária. Rev Soc Cardiol do Estado de São Paulo 1996; 6(suppl 2): 190-6.

33. Hsueh WA, Quinones MJ, Creager MA. Endothelium in insulin resistance and diabetes. Diabetes Reviews 1997; 5:343-52.

34. Diabetes Control and Complications Trial Research Group. The effect of intensive treatment of diabetes on development and progression of long-term complications in insulin dependent diabetes mellitus. N Eng J Med 1993; 329: 977- 86.
35. Feldt-Rasmussen B, Mathiesen ER, Jensen T, et al. Effect of improved metabolic control on loss of kidney function in type I (insulin-dependent) diabetic patients: an update of the Steno studies. Diabetologia 1991; 34: 164-70.

36. United Kingdom Prospective Diabetes Study (UKPDS). Intensive blood-glucose control with sulfonylureas or insulin compared with conventional treatment and the risk of complications in patients with type 2 diabetes. Lancet 1998; 352: 837.

37. Wilson PW, Cupples LA, Kannel WB. Is hyperglycemia associated with cardiovascular disease? The Framingham Study. Am Heart J 1991; 121: 586-90.

38. Hanefeld M, Fischer S, Julius U, et al. Risk factors for myocardial infarction and death in newly detected NIDDM: The Diabetes Intervention Study, 11 year follow-up. Diabetologia 1996; 39: 15777-83.

39. Johnstone MT, Creager SJ, Scales KM, Cusco JA, Lee BK, Creager MA. Impaired endothelium-dependent vasodilation in patients with insulin-dependent diabetes mellitus. Circulation 1993; 88: 2510-6.

40. Smiths P, Kapma JA, Jacobs MC, Lutterman J, Thien T. Endotheliumdependent vascular relaxation in patients with type 1 diabetes. Diabetes 1993; 42: 148-53.

41. Halkin A, Benjamin N, Doktor HS, Todd D, Vibert G, Ritter JM. Vascular responsiveness and cation exchange in insulin-dependent diabetes. Clin Sci 1991; 81: 223-32.

42. Asakawa H, Miyagawa J, Higashiyama S, et al. High glucose and hyperosmolarity increase heparin-binding epidermal growth factor-like growth factor (HBEGF) production in cultured human aortic endothelial cells. Cell Biochem Funct 1996; 14: 181-6.

43. Asakawa H, Miyagawa J, Hanafusa T, Kuwajima M, Matsuzawa Y. High glucose and hyperosmolarity increase secretion of interleukin-1 beta in cultured human aortic endothelial cells. J Diabetes Complications 1997; 11: 176-9.

44. Whikehart DR, Angelos P, Montgomery B. Effects of mannitol on cultured corneal endothelial cell Na, K-ATPase activity. Cornea 1995; 14: 295-9.

45. DECODE Study Group. Glucose tolerance and mortality: comparison of WHO and ADA diagnostic criteria. Lancet 354: 617-621, 1999. 